\title{
Salt Penetration in Whole Raw Tuna Frozen Onboard Vessel by Brine Immersion: An Industrial Study
}

\author{
JOHN DeBEER, FRED NOLTE, \\ CHRISTOPHER W. LORD, and JAVIER COLLEY
}

\section{Introduction}

The commercial tuna industry is a global business. More than a dozen species can be canned as tuna in the United States (Canned Tuna $\mathrm{SOI}^{1}$ ).

${ }^{1}$ SOI (Canned Tuna Standard of Identity). 21CFR161.190. 2001 (avail. at https://www.gpo. gov/fdsys/pkg/CFR-2002-title21-vol2/pdf/ CFR-2002-title21-vol2-sec161-190.pdf, accessed 5 May 2018).

John DeBeer (retired) was with Chicken of the Sea International, 2150 E. Grand Avenue, El Segundo, CA 90245; Fred Nolte is Principal at Fred Nolte Consulting, 2503 West 5th Ave, Vancouver BC, Canada V6K 1S9; Christopher W. Lord, is Principal at Pro-Tech International Consultants (1993), 50/75 Nuanjan Road, Kwang Klongkoom, Khet Buangkoom, Bangkok 10240 Thailand; and Javier Colley is with Chicken of the Sea Georgia Canning, 129 N. Commerce Drive, Lyons, GA 30436; Corresponding author is John DeBeer (email: jdebeer2005@ gmail.com). Mention of trade names or commercial firms is for identification purposes only and does not imply endorsement by the National Marine Fisheries Service, NOAA. Views or opinions expressed or implied are those of the authors and do not necessarily reflect the position of the National Marine Fisheries Service, NOAA.

doi: https://doi.org/10.7755/MFR.81.1.2
The primary species in volume and value are skipjack tuna, Katsuwonus pelamis; yellowfin tuna, Thunnus albacares; bigeye tuna, Thunnus obesus; tonggol, Thunnus tonggol; and albacore, Thunnus alalunga. These tunas are primarily caught by purse seiners and longline vessels. Pole-and-line boats using live baitfish (baitboats) are also used to capture the tuna, depending on the species and availability of baitfish and of near-shore processing stations (Hamilton et al. ${ }^{2}$; ISSF$^{3}$ ).

Skipjack tuna (SKJ), yellowfin tuna (YFN), bigeye tuna (BET), and other species of tuna are schooling fish. They are caught in large numbers by purse seiners that encircle the fish to

${ }^{2}$ Hamilton, A., A. Lewis, M. A. McCoy, E. Havice, and L. Campling. 2011. Market and industry dynamics in the global tuna supply chain. Pac. Is. Forum Fish. Agency, 95 p. (avail. at https://www. ffa.int/node/567, accessed 5 May 2018).

${ }^{3}$ ISSF (International Seafood Sustainability Foundation). 2018. Interactive Stock Status Tool (avail. at https://iss-foundation.org/about-tuna/ status-of-the-stocks/interactive-stock-statustool/, accessed 5 May 2018). capture them: schooling tuna are often seen at the ocean surface feeding on smaller fish (baitfish). Tunas and other schooling fish also often gather under floating objects in the ocean, such as $\operatorname{logs}$, seaweed, dead whales, etc. (Castro et al., 2002). For many years fishermen have built small structures or Floating Aggregating Devices (FADs) to try to attract schools of tuna. In the late 1970's, the use of FADs was proposed to reduce porpoise mortality in the Eastern Tropical Pacific (ETP) (DeBeer, 1980). FADs are so successful at attracting fish that currently, in 2018 , there are periodic closures of fishing on FADs for resource management and sustainability reasons $\left(\mathrm{ISSF}^{4}\right)$.

In 2016, the catch of commercial tunas was 4.9 million tons $\left(\mathrm{ISSF}^{3}\right)$. Most

${ }^{4}$ ISSF (International Seafood Sustainability Foundation). 2018. Mixed Results for Tuna Conservation, FAD Management and MCS Tools at IOTC (avail. at https://iss-foundation.org/mixedresults-for-tuna-conservation-fad-managementand-mcs-tools-at-iotc/, accessed 28 June 2018).
ABSTRACT-The commercial tuna industry is a global business. In 2016, the catch of commercial tunas was 4.9 million tons. Most of the tuna intended for canning is harvested at sea and needs to be chilled, or chilled and frozen at sea, and then processed into cans or other containers to preserve freshness and wholesomeness. Twothirds of this global catch of tuna are frozen in salt (sodium chloride) brine. The U.S. FDA offers recommended dietary allowances for many nutrients, including sodium, and encourages the consumer to lower their sodium intake.

Depending on a host of factors, the direct contact between brine and the fish will result in some salt (sodium) uptake into the fish muscle. To better understand the impacts of these factors on sodium uptake, this paper describes a multiple regression study of salt penetration in tuna frozen in salt brine and offers suggestions to reduce the salt levels in the tuna delivered to the canneries. The following are best practices to produce excellent quality purse seine fish:

1) Always have enough cold refrigerated seawater $(\mathrm{RSW})\left(-1^{\circ} \mathrm{C}\right.$ or $\left.30^{\circ} \mathrm{F}\right)$ or cold brine $\left(-20^{\circ} \mathrm{C}\right.$ or $\left.-4^{\circ} \mathrm{F}\right)$ to receive and chill the maximum expected catch. Do not catch the fish if it cannot be chilled immediately.

2) Quickly transfer the fish from the net to the wells with chilled RSW or cold brine. Brail fast.

3) Do not overpack the wells. This is a critical practice to achieve rapid chilling and freezing rates, greatly reduce physical damage, and facilitate easier and faster unloading.

4) Restrict the time the tuna spends in the
$R S W$. If the chilled tuna remains in $R S W$ for a maximum of 5 days, brine the well. If the well is only partially filled, spray the brine over the fish. If the fish size is small (i.e., Auxis spp.), the amount of time stored in RSW before brining may need to be even less.

5) Freeze the fish completely to a minimum of $-12^{\circ} \mathrm{C}\left(10.4^{\circ} \mathrm{F}\right)$ backbone or core temperature.

6) Dry the wells (remove the brine) after the fish have been completely frozen.

7) Unload the fish dry and frozen at $-20^{\circ} \mathrm{C}\left(-4^{\circ} \mathrm{F}\right)$, if possible. The colder the better for the quality of the fish.

The tuna fishing restrictions in 2019 include full retention of tunas so all usable fish need to be transported to markets for use, including the very small fish, which could have a very high salt content. 
were SKJ (57\%) and YFN (30 \%), and, $85 \%$ of the SKJ and $65 \%$ of the YFN were captured by purse seiner or bait boat $\left(\mathrm{ISSF}^{3}\right)$. Tuna intended for canning needs to be chilled, or chilled and frozen at sea, and then processed to preserve freshness and usability.

Most tuna landed by purse seiners or bait boats are chilled whole in refrigerated seawater (RSW) without bleeding, or removing the gills, or gutting, and then frozen in cold salt (sodium chloride) brines (DeBeer ${ }^{5}$ ). Over 68\% of the world's tuna catch, or about 3.3 million tons, is handled this way. The exact method of chilling and freezing the fish may vary from vessel to vessel, but all involve direct contact of RSW and/or brine with the fish. Depending on a host of factors, this direct contact between brine and the fish will result in some salt uptake into the fish muscle (Farber, 1955; Burns, 1985). For tuna canners, all brine-frozen tuna is assumed to have absorbed some salt and cannot be used for low-sodium tuna packs $\left(\right.$ Colley $\left.^{6}\right)$. Air-blast-frozen tuna must be used for low-sodium packs and are not part of this study.

There are four parts to this paper: 1) a mini-review of brine freezing tuna, 2) a report of an industrial study on salt penetration in purse-seine-caught tuna landed at a cannery in San Diego, Calif., 3) a discussion of the recommended actions based on the knowledge gained from the study, and 4) an overview of current regulations or restrictions faced by the purse seiners in 2019 that impact the delivery of high quality tuna to canneries. In the 1970's, the excessive salt in whole raw tuna captured by purse seiners and delivered to the U.S.-based canneries was a serious problem. The following describes how the problem was addressed, the solutions determined, and suggestions for how these techniques can be used again, as needed.

${ }^{5}$ DeBeer, J. Personal observ. (email: jdebeer2005 @gmail.com).

${ }^{6}$ Colley, J. Chicken of the Sea, Intl., Lyons, GA. Personal commun. 27 June 2018 (email: Javier. colly@thaiunion.com).

\section{Brine Immersion Systems}

Brine immersion systems have been used to freeze tuna for nearly 100 years because cold circulating brine can quickly transfer large amounts of heat from the warm tuna to the refrigeration system, and away from the fish. A brine immersion system is the only technique that can effectively freeze a large volume of tuna caught in one set by a purse seiner (easily over 200 300 metric tons (t) in a set, see below). Salt, used as the freezing medium, is inexpensive and easily available throughout the world (Farber, 1955; Slavin and Finch, 1969).

Brine immersion systems for fishing vessels were tested in the 1920's by Almy and Field (1921), and the first systems were used on tuna bait boats in the early 1930's (Slavin and Finch, 1969). Prior to using brine to freeze the tuna, long-range bait boats out of California used ice to preserve the tuna. By the late 1930's, complete loads of fish held on ice were being rejected at canneries in San Diego and San Pedro owing to decomposition because the vessels were out at sea for too long (Farber, 1955; Wright, 1991).

The conversion of the bait boats from ice to brine preservation systems happened very quickly in the late 1930's and early 1940's (Wright, 1991). Godsil (1938) reported a mix of boats using brine and ice in his report "The High Seas Tuna Fishery of California" and also reported on the conversion process from an ice boat to a brine freezing vessel.

Tuna purse seiners were initially used to catch tuna starting in the 1920's (Godsil, 1938; Scofield, 1951), but the major changeover to purse seining happened because of the invention and commercial availability of nylon nets and a mechanized net retrieval system using the Puretic power block. This revolution started in San Diego, Calif., in the late 1950's (Felando and Medina, 2012). Bait boats were converted to purse seiners first, and then new steel purse seiners were built. Between 1958 and 1969, 94 tuna clippers (bait boats) were converted to purse seiners, and, between 1961 and 2000, over 160 new tuna seiners were built in the United States or acquired for entry into the U.S. fleet (Felando and Medina, 2012). By 1980, the size of tuna boats delivering to California canneries ranged from $600 \mathrm{t}$ to 1,500 $t\left(\right.$ DeBeer $\left.^{5}\right)$.

The average amount of tuna caught by a purse seiner in the late 1970's in a single successful set was about $10 \mathrm{t}$, but, the catch could range from zero to over $200 \mathrm{t}$ (DeBeer, 1980). After the tuna were captured, they were scooped aboard using large net buckets (brailing) and put into wells (compartments) filled with RSW kept at $-1^{\circ} \mathrm{C}\left(30^{\circ} \mathrm{F}\right)$ to cool the fish quickly (Farber, 1955; Burns, 1985). Each well was outfitted with refrigeration piping and circulation pumps that were connected to the vessel's refrigeration system. The piping in the well chilled the RSW and brine. The amount of applied refrigeration can be controlled separately for each well. The capacity of the wells ranged from 40 to $110 \mathrm{t}$, depending on their location in the vessel. The primary refrigerant that flows through the inside of the piping on the purse seiners was and is ammonia.

The chief engineer (CE) on a tuna boat is the person in charge of chilling and freezing the fish, in addition to maintaining the engine and vessel's machinery. At the time of this study (early 1980's), the tuna was generally stored in RSW until the well was filled, at which time salt was added; the well was brined. If a well was not filled in 7 days, the RSW would start to develop some odors (Farber, 1955). Some CEs elected to brine the well at that time, while others chose to change the seawater and hold the tuna in RSW for a longer period.

The reason for holding the tuna in RSW instead of brining the well immediately was purely economic. If the tuna were immediately frozen in brine, the thought was, there was a lot of wasted space in the well. As tuna freeze, they can expand their volume by up to $10 \%$ (Burns, 1985). More tuna can be packed into a well when 
they are unfrozen and flexible, than when they are hard frozen $\left(\right.$ DeBeer $\left.^{5}\right)$.

If a well was filled during a single set, the usual practice was to chill the tuna for $24 \mathrm{~h}$ in the RSW until the tuna were at $-1^{\circ} \mathrm{C}\left(30^{\circ} \mathrm{F}\right)$. The RSW was then pumped out of the well and cold brine with a freezing point of $-20^{\circ} \mathrm{C}$ $\left(-4^{\circ} \mathrm{F}\right)$ was pumped into the well to freeze the tuna (Burns, 1985). If no cold brine was available, salt was simply added to the RSW, and the refrigeration target temperature was lowered to freeze the fish. The tuna was then stored in the cold circulating brine for periods of several days up to several months. On some occasions, after the tuna was frozen in brine for 72-96 h, the brine removed, and the tuna were stored frozen "dry" (brine removed from the well) (Farber, 1955).

\section{Transport and Delivery Methods}

Before the 1950's, catcher vessels unloaded directly to a cannery. Beginning in the 1950's, the frozen tuna could also be transported (transshipped) on another vessel from a unloading port and delivered to a cannery $\left(\right.$ Sylvester $\left.^{7}\right)$. The fish could then be brought from Peru, Panama, Africa, or any fishing grounds to a cannery while stored dry frozen on bulk cargo freezer carriers (Goulding, 2000) or in refrigerated containers.

Before the 1980's, the practice of loading wells on the purse seiners was to pack the fish in the wells as tightly as possible. As the fish were frozen, they would expand and freeze together. The tuna would then need to be tempered or thawed somewhat to unload them at the canneries by the catcher vessel (Lassen and Rawlings, 1959; DeBeer ${ }^{5}$ ).

The method of partial thawing or tempering for unloading in those years is described in Lassen and Rawlings (1959). To do so, the ammonia fed to the coils in the wells was turned off. The ammonia may have been turned off a week or so before the unloading of that well could proceed. The

\footnotetext{
${ }^{7}$ Sylvester, J. 2018. Shared excerpts from "The First Forty Years", Marine Chartering Co., Inc., 163 p. (email: John@chartering.com).
}

brine circulation continued, the brine warmed up, and so did the fish. As the fish and brine warmed up, the fish absorbed some salt. Additionally, the CEs had to add more salt to the brine to maintain the brine concentration and hold the freezing point below the temperature of the fish to prevent the wells from icing up and impeding the unloading. The CEs normally tried to unload the tuna as cold as possible and still facilitate unloading. At the time of this study in 1980, the SKJ and small YFN were unloaded at between $-8^{\circ} \mathrm{C}$ and $-4^{\circ} \mathrm{C}\left(18^{\circ} \mathrm{F}-24^{\circ} \mathrm{F}\right)$, and the large YFN at $-5^{\circ} \mathrm{C}$ to $-2^{\circ} \mathrm{C}\left(22^{\circ} \mathrm{F}-28^{\circ} \mathrm{F}\right)$.

\section{Salt Content of Fish}

Freshly caught tuna has a salt content of $0.1 \%$ to $0.2 \%$ (Karrick and Thurston, 1967). Both RSW and brine have higher salt content, but, when tuna is stored in RSW or brine, over time, tuna will absorb salt from them during storage. The tuna received at the cannery in the early 1980's had a salt content that ranged from $0.2 \%$ to over 5\% (Lang and Farber, 1939; Karrick and Thurston, 1967; DeBeer ${ }^{5}$; Nolte $^{8}$ ). This difference depended on a few factors including the size of the fish, the style of fishing boat, method of catch, and whether air-blast frozen, received chilled on ice, or from purse seiners with brine systems from extended trips.

\section{Salt Penetration}

Salt can penetrate the tuna flesh during two or more phases of the onboard handling and freezing treatment. Both RSW and brine have higher concentrations of salt than the fish and the process of osmosis forces salt across the fish skin and into the fish flesh. Seawater has about $3.5 \%$ salt by weight (Burns, 1985), so RSW has is a concentration gradient difference of about 35 times across the skin of fresh tuna. Brine, with a freezing point of $-20^{\circ} \mathrm{C}$ $\left(-4^{\circ} \mathrm{F}\right)$, is about $23 \%$ salt (Burns, 1985), and a concentration gradient across the tuna skin of about 100-fold.

${ }^{8}$ Nolte, F. Fred Nolte Consulting, Vancouver, B.C., Can.. Personal commun, 14 May 2018 (email: nolte@shaw.ca).
When tuna is stored in RSW, the skin breaks down over time, and the rate of salt penetration increases. After tuna is finally frozen in brine and held at $-12^{\circ} \mathrm{C}\left(10.4^{\circ} \mathrm{F}\right)$, salt uptake proceeds more slowly but continues until the brine is removed. If the fish has spent an excessive time in RSW, then damaged skin could allow the rate of salt uptake to be much more (Lang and Farber, 1939).

The salt content, well by well, and even fish by fish, in a load of purse seiner tuna in the early 1980's could easily vary from $0.3 \%$ to $5 \%$ for the reasons previously described. The salt analysis from different fish in a single well could vary from less than $1 \%$ to almost 5\% (DeBeer $\left.{ }^{9}\right)$. This variation could happen if the tuna were put in RSW and held there for 7-10 days or more before more fish were added and then finally brined.

As freshly caught tuna was added to the well, the RSW would warm up. The previously chilled tuna would warm up and allow more salt penetration into the flesh. The CEs would sometimes add salt to keep the RSW at $3.5 \%$ salt concentration to prevent the refrigeration coils from icing up $\left(\mathrm{DeBeer}^{5}\right)$. This process could occur several times until the well was filled with tuna, and the RSW is removed and replaced with brine for freezing. When catcher vessels reached the cannery, samples of tuna for salt analysis were randomly drawn from every well. The samples could have come from tuna kept for long periods in RSW or from tuna kept in RSW for only a short period of time, or different sizes, and thus varied in salt content.

Purse seiners were bringing in tuna with high levels of salt content, but there was not a lot of information available to share with the CEs on how to reduce the salt penetration in the tuna on a real time basis. Many of the CEs on the purse seiners believed that there was no more salt penetration after the fish was frozen, even though a daily duty for the CE was to check

90Beer, J. Unpubl. data (email: jdebeer2005@ gmail.com). 
the salinity of the brine and add salt as needed to keep the freezing point of the brine in the proper range. This additional salt was to prevent the entire well from icing up because there was not enough salt in the brine (Burns, 1985). The freezing brine needs to be kept at $23 \%$ salt to maintain the low temperatures $\left(-20^{\circ} \mathrm{C},-4^{\circ} \mathrm{F}\right)$ and remain liquid without ice formation.

The CEs did not know where the salt was going when the wells iced up, but they were certain the salt did not penetrate the fish when it was frozen. There was very little formal training for CEs on purse seiners as it was all on-the-job training. A short "Refrigeration Manual for Tuna Clippers" (bait boats) had been developed (Lassen and Rawlings, 1959), but it was out of print and was not relevant for purse seiners with their larger and more sophisticated RSW and brine systems.

Salt penetration into the tuna from RSW and brine occurs during all phases of chilling, freezing, and thawing. The conventional wisdom of many CEs at that time was that the following variables were the most important.

1) Size of tuna: smaller tuna seemed to absorb more salt (measured as a percent by weight) than larger tuna. The surface-area-to-volume ratio is greater for smaller tuna than it is for large tuna.

2) Species of tuna: SKJ were thought to absorb more salt than the same size YFN when treated under the same conditions.

3) Time of storage in RSW: tuna stored for long periods in RSW seemed to absorb more salt than tuna not stored in RSW. Tuna skin slowly deteriorates in RSW; thus, this permits more salt penetration into the tissue when the tuna is eventually frozen and stored in brine.

4) Time spent in brine: tuna seemed to absorb more salt the longer it was stored in dense cold brine, but it was thought by many CEs that once the fish was frozen in brine there was no more salt penetration, instead of only slowing the process.
5) Time/temperature of thaw: tuna thawed or tempered in brine and unloaded at higher temperatures seemed to have a higher salt content than those unloaded at colder temperatures.

\section{Dietary Sodium}

Since the 1960's and 1970's, much information had been published about excessive sodium $\left(\mathrm{Na}^{+}\right)$in the American diet (Wartella et al., 2010; CSPI ${ }^{10}$; $\mathrm{IOM}^{11}$ ). The first voluntary guidelines from the FDA were published in 1982 (USFDA, 1982). FDA regulations on salt and sodium are described in Trumbo ${ }^{12}$. Tuna with $0.8 \%$ salt has $178 \mathrm{mg} \mathrm{Na}^{+}$in a 2-oz serving (the seafood serving size in 2018). Tuna with $1.1 \%$ salt has $245 \mathrm{mg} \mathrm{Na}^{+}$in a $2-\mathrm{oz}$ serving.

Based on press reports that there might be sodium regulations coming in the late 1970's, Van Camp Seafood started a raw tuna quality improvement program to reduce the salt in the fish landed from the purse seiners and bait boats in its San Diego, Puerto Rico, Manta, Ecuador, and American Samoa operations. Two of the authors $\left(\right.$ DeBeer $^{5}$; Lord $^{13}$ ) worked on that program in San Diego and American Samoa in that era.

\section{Purpose of the 1980 Study}

The purpose of the study in 1980 was to determine which factors contributed most to salt penetration into whole raw tuna on fishing vessels. The results of this study would then be used to communicate with the CEs and provide them with practical solu-

${ }^{10} \mathrm{CSPI}$ (Center for Science in the Public Interest). 2017. Sodium: A timeline (avail. at https:// cspinet.org/resource/sodium-timeline, accessed May 12, 2018).

${ }^{11} \mathrm{IOM}$ (Institute of Medicine). 2010. Strategies to reduce sodium intake in the United States. The Natl. Acad. Press, Wash., D.C. (avail. at https://www. ncbi.nlm.nih.gov/books/NBK50956/pdf/Bookshelf_NBK50956.pdf, accessed 5 May 2018).

${ }^{12}$ Trumbo, P. R. 2008. FDA regulation of salt and sodium (avail. at https://pdfs.semanticscholar.org/ presentation/c70e/d4fac211d185fce3151e8b5f2a 9072f9f3a6.pdf, accessed 12 May 2018).

${ }^{13}$ Lord, C. W. Pro-Tech Intl., Bangkok, Thailand. Personal commun., 14 May 2018 (email: protech1993@live.com). tions to address high-salt fish problems. With the understanding of the key variables and impacts, proper procedures could be initiated to reduce the salt levels.

\section{Methods and Materials}

The data used in this study was collected from purse seiners delivering tuna to Van Camp Seafood's cannery in San Diego, Calif. The variables chosen for this analysis were the following:

1) SALT\%: Percentage of salt in the raw tuna unloaded at the cannery, which was collected during the routine sampling of the salt content of incoming tuna.

2) SPECIES: Either YFN or SKJ: expressed as a "dummy" variable.

3) SIZE: The size of the tuna depended on the species, $1=$ small SKJ or very small YFN (under $6 \mathrm{lb}$ ); $2=$ large SKJ or small YFN (6 to $15 \mathrm{lb}$ ); 3 = medium YFN (15 to 30 lb); 4 = large YFN (31 to $60 \mathrm{lb}$ ); 5 = extra-large YFN (over $60 \mathrm{lb}$ )

4) DAYSRSW: The maximum number of days that any tuna spent in RSW before the well was brined. For example, if DAYSRSW was 10 , then at least some of the tuna had spent 10 days in RSW.

5) DAYSBRIN: Number of days the tuna spent frozen in brine.

6) UNLDTEMP: The temperature $\left({ }^{\circ} \mathrm{F}\right)$ at which the tuna was unloaded.

This process was full-scale industrial sampling of salt content of the tuna. The fish in every well of each vessel were sampled for salt: each lot was a single fish well. The fish were collected from throughout the well by species by size. Ten or 15 fish by species by size per lot were randomly sampled for salt, depending on the fish size. The samples were composited for analysis and reporting; five samples per composite or observation. A pie-shaped section of the dorsal area near the first dorsal fin was the preferred sampling area (Fig. 1). This piece of flesh included meat from just below the skin to the core (backbone). The species and size group of the fish 


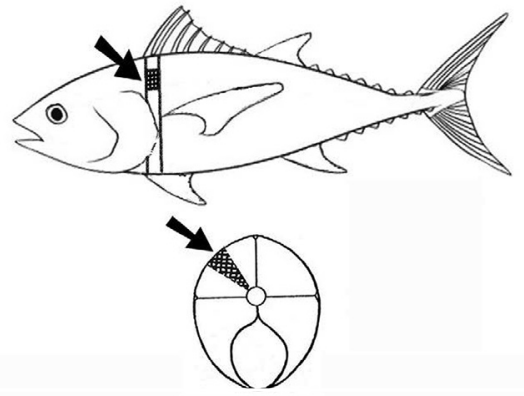

Figure 1.-Salt sampling location.

was recorded at the time of collection by the sampler. The days in RSW and brine were collected from the CEs log. The unloading temperatures of the fish thawed in brine were collected by direct observation with a dial thermometer $\left(\right.$ DeBeer $\left.^{5}\right)$ or from the CEs log.

Although the variables mentioned in the previous section were considered to contribute to salt penetration into the tuna, the impact on salt uptake of each variable was unknown. A multiple (stepwise) regression study was selected for the data analysis (Hair et al., 1979). The regression models were run on the GE timeshare system, on the sub-system STAT II**.

Each of the variables had a different magnitude, due to a different distribution of information. The SIZE variable was integer valued with groups from 1 to 5. The SPECIES variable was a dummy variable expressed as 1 or 2 . The SALT\% variable was a positive real number, had a continuous distribution, and ranged from $0.3 \%$ to $8 \%$. The DAYSRSW ranged from 0 to 25 , and the DAYSBRIN ranged from 6 to 120. To adequately assess the relative contribution of each variable to the equation, Beta or standardized coefficients were analyzed as well (Hair et al., 1979).

This study progressed in several steps using three different sets of data. Database \#1 (DB1) consisted of 332 observations collected from 14 vessels. Variables collected were as listed above except without UNLDTEMP. Database \#2 (DB2) consisted of 213 observations generated from 9 ves- sels with the same variables but included UNLDTEMP. In DB1, an individual vessel may have had two trips sampled, and, in DB2, the data may have been collected from some of the same vessels as collected in DB1. Database \#3 (DB3) consisted of 113 salt observations for a single vessel (M/V Odette Therese).

In the initial testing, regression Models 1 through 4 were developed with DB1. In the confirmatory testing, three regression models, Models 5 through 7, were developed using DB2.

\section{DB1-Initial Testing}

In the initial testing, regression Models 1 through 4 were developed using DB1, starting with the full set of data, and then with subsets and/or data combinations. Model 1: A stepwise regression analysis was run on DB1 using all the observations. Model 2: The stepwise regression was rerun on all cases from DB1 with less than 3\% salt. Model 3: The stepwise regression was run on all cases from DB1 with salts greater than 3.0\%. Model 4: All 332 observations from DB1 were rerun with a stepwise regression to test for interactions. The following interactions were used: SALT\% vs. each of the following: SIZE, DAYSRSW, DAYSBRIN, (SIZE*DAYSRSW*DAYSBRIN), (SIZE* DAYSRSW), and (SIZE*DAYSBRIN).

\section{DB2-Confirmatory Testing}

To confirm the hypothesis formed and tested in Models 1 through 4, DB2 was generated using completely new data. This database, however, included an additional variable of unloading temperatures $\left({ }^{\circ} \mathrm{F}\right)$ of fish partially thawed (tempered) in brine. The stepwise regression analysis was run again on this data. This data contained only six observations with salt results over $3 \%$.

The variables in Model 5 were SALT\% vs. DAYSRSW, SIZE, DAYSBRIN, and SPECIES. The variable UNLDTEMP was not included in the data so the results could be compared with Models 1 through 4. Model 6: because DAYSRSW played such im- portant roles in Models 1 through 4, DAYSRSW and SPECIES were forced into Model 5. Model 7: to test the hypothesis that the unloading temperature might contribute to salt penetration, a stepwise regression was run on DB2 with the variables SALT\% vs. each of the following: SIZE, DAYSBRIN, SPECIES, DAYSRSW, and UNLDTEMP.

\section{DB3 - Observations from the $\mathrm{M} / \mathrm{V}$ Odette Therese}

In 1983, the $\mathrm{M} / \mathrm{V}$ Odette Therese made a long trip out of San Diego, Calif., to the Western Tropical Pacific Ocean (WTP). The CE was requested to dry some wells, and he dried the entire cargo of fish. Only the salt data by size and unloading temperatures were collected and available for analysis, comparison, and reporting.

\section{Results}

The data summaries for DB1, DB2, and DB3 are presented as scatterplots of selected data. Figures 2-4 compare selected data from DB1: Figure 2 shows the relationship of salt levels to fish size, Figure 3 salt levels to days in RSW, and Figure 4 salt levels to days in brine. Figures 5-6 compare selected data from DB2: Figure 5 compares the salt levels to days in RSW, and Figure 6 the salt level to days in brine. Figure 7 compares the scatter plots from DB1 and DB3. The one thing very clear in these scatterplots is the extremely wide variation in the salt levels with the comparison attributes, thus the need for a multiple-regression analysis to understand the impact of each of these variables.

\section{Knowledge Gained from Regression Analysis of DB1}

A summary of the stepwise regression results from Model 1 is presented in Table 1. The first variable to enter the equation was DAYSRSW, the second was SIZE, and the third was DAYSBRIN. All these variables contributed significantly (Sig. $=100 \%$ ) to the model. The R-Squared (RSQ) value is 0.48 , thus, $48 \%$ of the variation in the data can be accounted for by the 


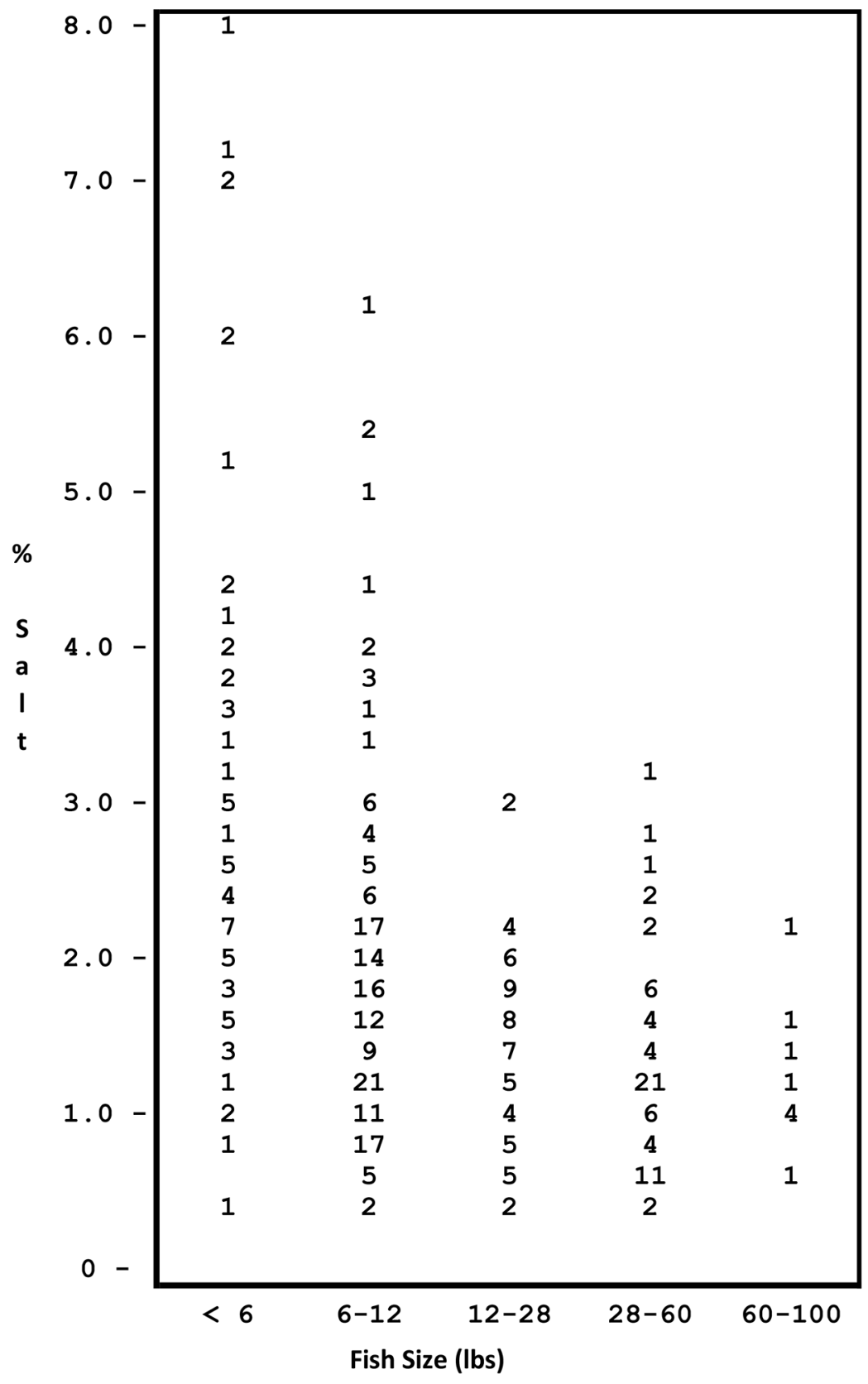

Figure 2.- Percentage salt in tuna vs. fish size for DB1. This scatterplot shows the number of observations for each fish size.

regression equation and these three variables. An RSQ of 0.48 is not particularly good for a predictive equation; however, it's very significant to explain the overall impact of the variables. The Beta coefficients for Model 1 were 0.43 for DAYSRSW, -0.42 for SIZE, and 0.32 for DAYSBRIN. Thus, DAYSRSW and SIZE impact the equation equally, although in opposite directions, and DAYSBRIN, although very important, caused less of a change in this model than either of the other variables.
An inspection of the residuals (the predicted salt levels vs. the actual salt levels) plotted against the actual salt levels (Fig. 8) showed a non-random pattern of the residuals. Thus, there were apparently other factors that contributed to salt penetration. Most of the high unexplained values occurred above 3\% salt. To test whether the variables affect salt penetration at levels above and below 3\% differently, two other models were run on subsets of DB1.

Model 2 only used observations with less than 3\% salt from DB1, and the results of the regression analysis are presented in Table 2 . In this mod$\mathrm{el}$, the first variable to enter the equation was DAYSBRIN, the second was SIZE, and the last was DAYSRSW. All variables contributed significantly to the equation at the $99 \%$ or greater level. This order of entry is opposite of the variables in Model 1. The RSQ is 0.40 , thus $40 \%$ of the variation in the data was accounted for by the regression model. The Beta values were 0.49 for DAYSBRIN, -0.37 for SIZE, and 0.12 for DAYSRSW. For salt levels less than $3 \%$, the model indicates that the length of time that the tuna spend in brine is 4 times more important than the time spent in RSW and 1.3 times as important as SIZE. The scatterplot of the residuals vs. the predicted salts, not shown, had no apparent trend; thus, the data used in this model appears to be homoscedastic.

Model 3 used only observations with greater than 3\% salt from the same dataset: the regression results are presented in Table 3. Only two variables entered the equation: DAYSRSW $($ Sig. $=100 \%)$ and SIZE (Sig. $=$ 99\%). The variable DAYSBRIN did not enter the equation. The RSQ was 0.51 , the Beta values were 0.66 for DAYSRSW and -0.32 for SIZE. The scatterplot of the residuals vs. the predicted salts, not shown, had no apparent trend. The implications of this analysis are that for these commercial samples at least, most of the problems of excessive salt (over 3\%) in the raw tuna, were caused by holding the tuna in RSW for too long. This analy- 


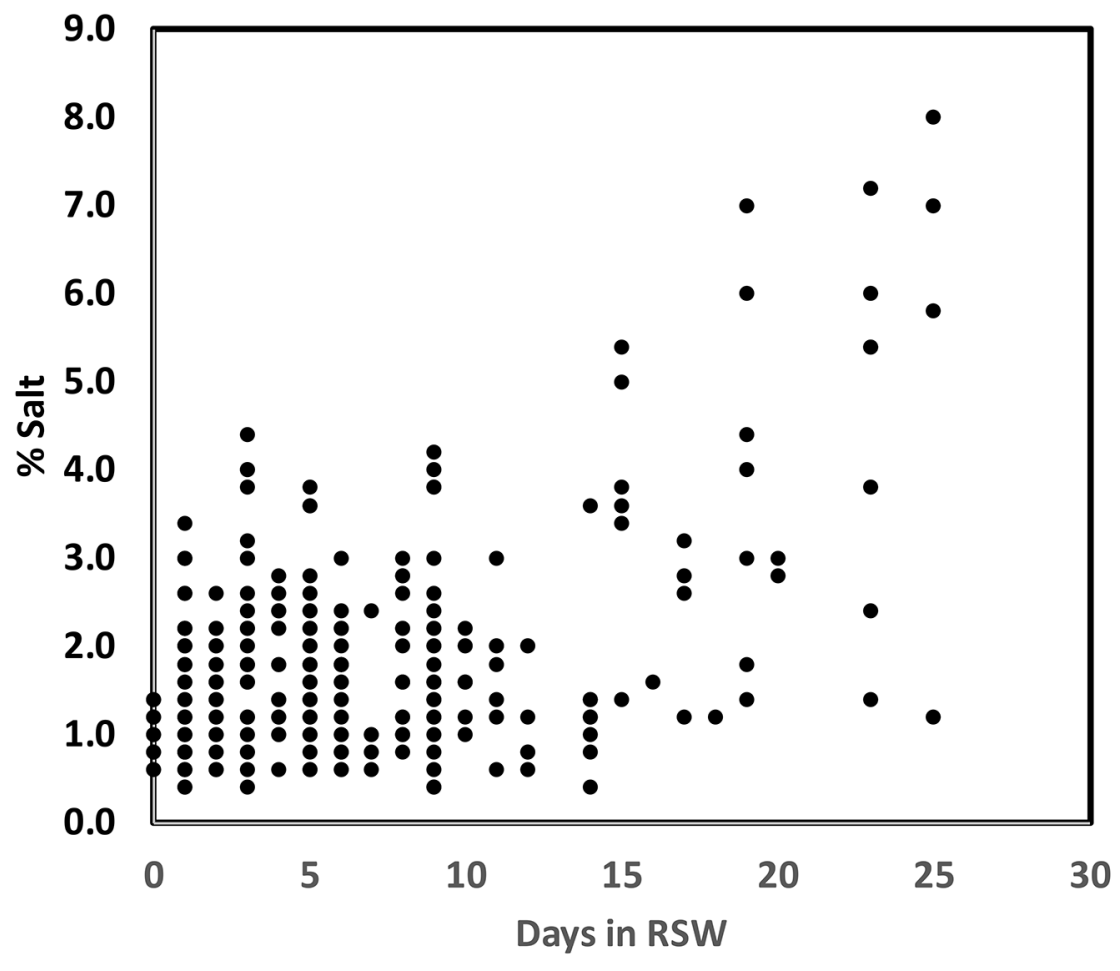

Figure 3.- Percentage salt in tuna vs. days in refrigerated seawater for DB1.

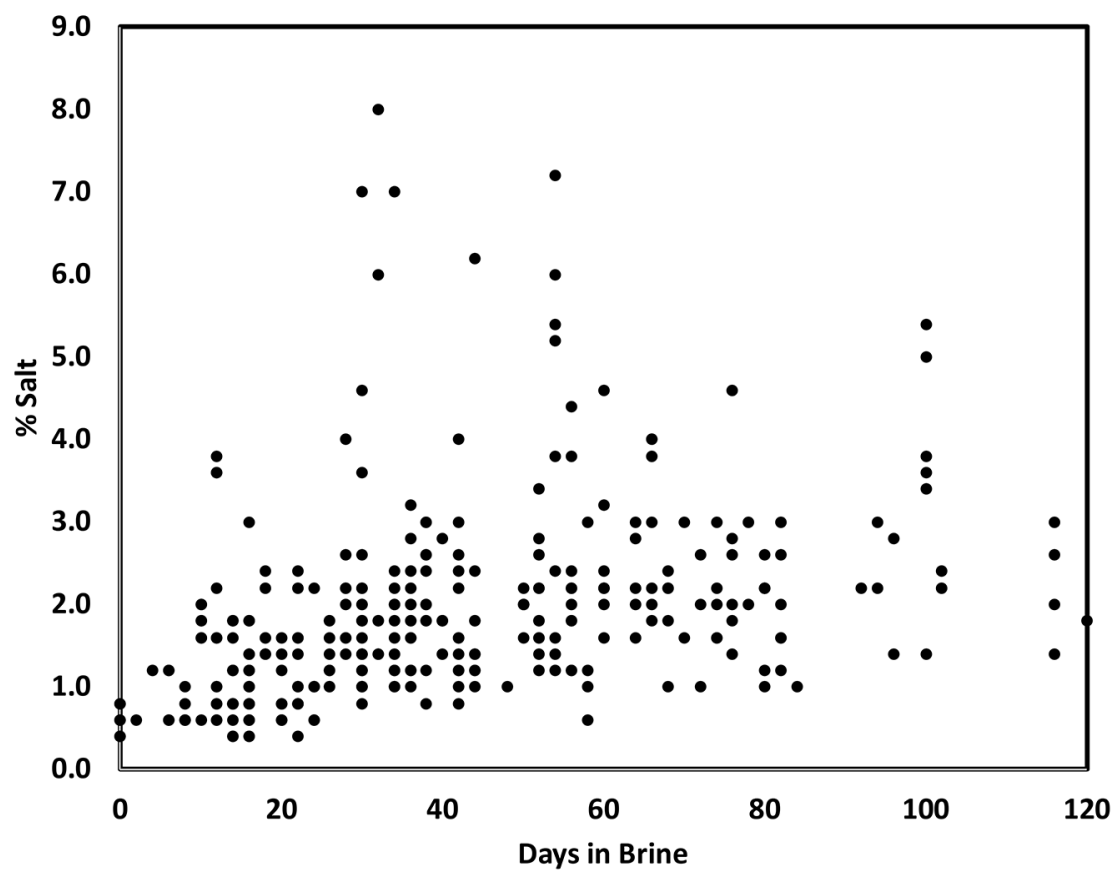

Figure 4. - Percentage salt in tuna vs. days in brine for DB1. sis indicates that many cases of highsalt fish could be prevented by advising the tuna fishermen to hold the tuna in RSW for a maximum of 5 days, and then freeze the tuna in brine.

Model 4 tested the interactions of some variables with each other in all observations of DB1. The regression results are shown in Table 4 . The resulting equation had 3 variables with a significance of Sig. $=100 \%$. The first term to enter was DAYSRSW, the second was (SIZE * DAYSRSW), and the third was DAYSBRIN. The RSQ was 0.53 , the Beta values were 0.88 for DAYSRSW, -0.59 for (SIZE * DAYSRSW), and 0.44 for DAYSBRIN. Note in this case that the variable SIZE did not enter the equation, however, SIZE was accounted for by the second term. The scatterplot of the residuals (not shown) was not homoscedastic.

\section{Knowledge Gained from Regression Analysis of DB2}

Models 5, 6, and 7 were verification models, run on a different set of data, DB2. Model 5 used the full set of observations from DB2, except for UNLDTEMP. The regression results are presented in Table 5 and only two variables were significant to the model. The first was SIZE, and the second was DAYSBRIN: both were significant at the $100 \%$ level. The RSQ was 0.58 , and the Beta values were -0.60 for SIZE and 0.34 for DAYSBRIN. SPECIES and DAYSRSW did not enter the model. No residuals were plotted for this data.

Model 5 can best be compared with Model 2 because there were only six cases of high salt (over 3\%) in this dataset (Table 6). In the case of Model 2, SIZE was twice as important as DAYSBRIN for predicting salt in tuna flesh. By comparison, in Model 5, DAYSBRIN was 1.3 times as important as SIZE and 4 times as important as DAYSRSW. Note that the coefficients for DAYSBRIN are very similar between the models.

In Model 6, the variables SPECIES and DAYSRSW were forced into the equation: the regression results and re- 
siduals are not shown. The Beta values were -0.63 for SIZE, 0.34 for DAYSBRIN, 0.03 for SPECIES, and 0.01 for DAYSRSW. This means that for data from DB2 at least, SPECIES and DAYSRSW contributed virtually nothing to Models 5 and 6.

Model 7 included the unloading temperature (UNLDTEMP) of the tuna thawed or tempered in brine; the regression results and residuals are not shown. In this regression model, the RSQ was 0.59 , as compared to 0.58 for Model 5, thus, the RSQ improved by only 0.01 . The Beta values were -0.59 for SIZE, 0.38 for DAYSBRIN, and 0.13 for UNLDTEMP. Thus, in this model, SIZE is almost twice as important as DAYSBRIN, and SIZE is about 4.5 times as important as UNLDTEMP. Although the UNLDTEMP variable did not contribute much to the equation, the significance of the findings implies that higher thawing or tempering temperatures while the fish remain in dense brine do contribute to higher salt level. This also makes intuitive sense.

\section{Knowledge Gained from Analysis of DB3 vs. DB1}

A side by side comparison of the salt samples by fish size from DB1 and DB3 (the M/V Odette Therese data) is shown in Figure 7. The fish from DB1 were stored in cold brine for many weeks and thawed or tempered in brine, while the fish from the $\mathrm{M} / \mathrm{V}$ Odette Therese was stored dry (the brine was removed) soon after being frozen and was unloaded dry at $-11^{\circ} \mathrm{C}\left(12^{\circ} \mathrm{F}\right)$. It is very apparent how much the salt levels were reduced by "drying" the wells, and it is especially noticeable in the smaller fish. All the salt levels from the M/V Odette Therese were $2 \%$ salt or less, and $85 \%$ of the salt levels were $1 \%$ salt or less. Contrasted with the fish from DB1, where only $70 \%$ of the salt levels were $2 \%$ or less, and only $24 \%$ were $1 \%$ salt or less.

\section{Discussion}

A stepwise multiple regression analysis was conducted to test five vari-
Table 1.-Results of regression analysis for Model 1 (II cases included).

\begin{tabular}{lclcccccr}
\hline Cases & Step & Variable & F & ADJ RSQ & Coef & S.E. & Sig. \% & Beta \\
\hline 332 & 1 & DAYSRSW & 86.3 & .21 & .089 & .008 & 100 & .43 \\
& 2 & SIZE & 94.6 & .38 & -.480 & .045 & 100 & -.42 \\
& 3 & DAYSBRIN & 67.2 & .48 & .015 & .002 & 100 & .32 \\
& Constant & & & 1.805 & & & \\
& STD Error Estimate & & & .844 & & & \\
\hline
\end{tabular}

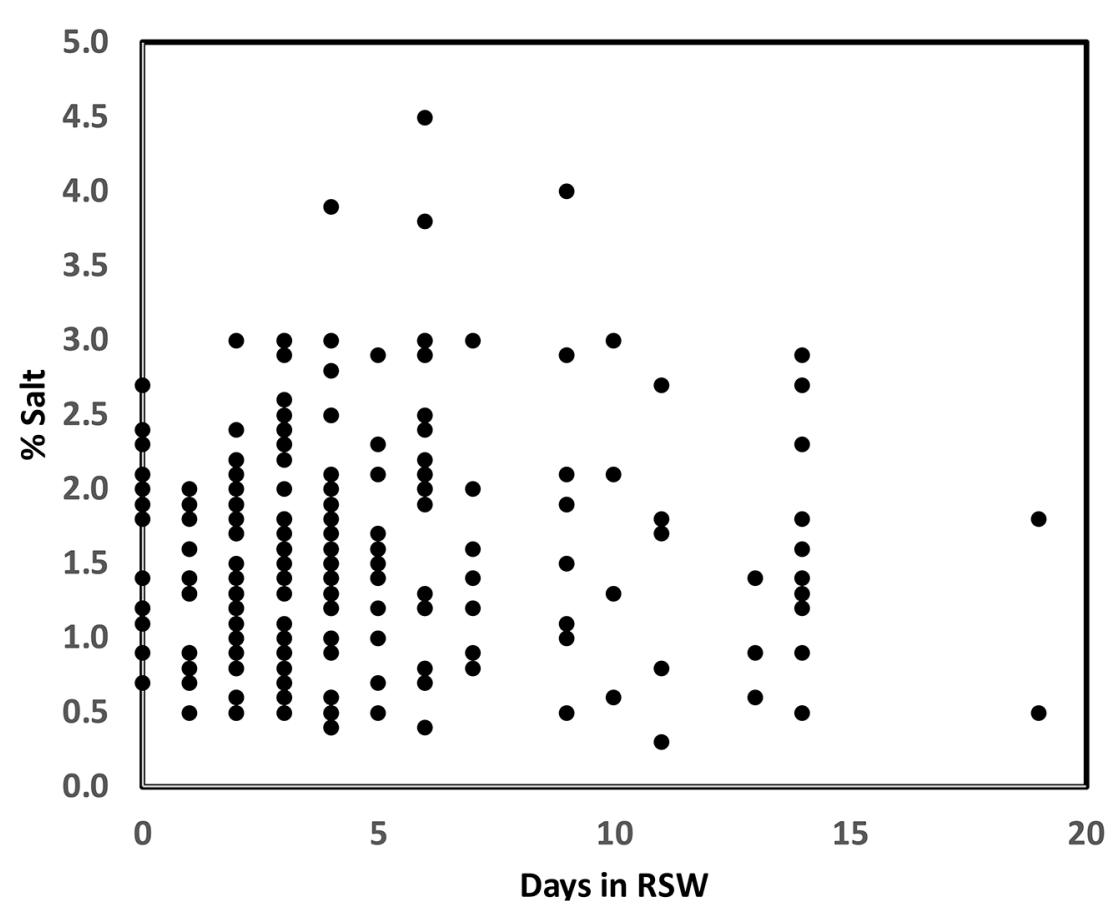

Figure 5.- Percentage salt in tuna vs. days in refrigerated sea water for DB2.

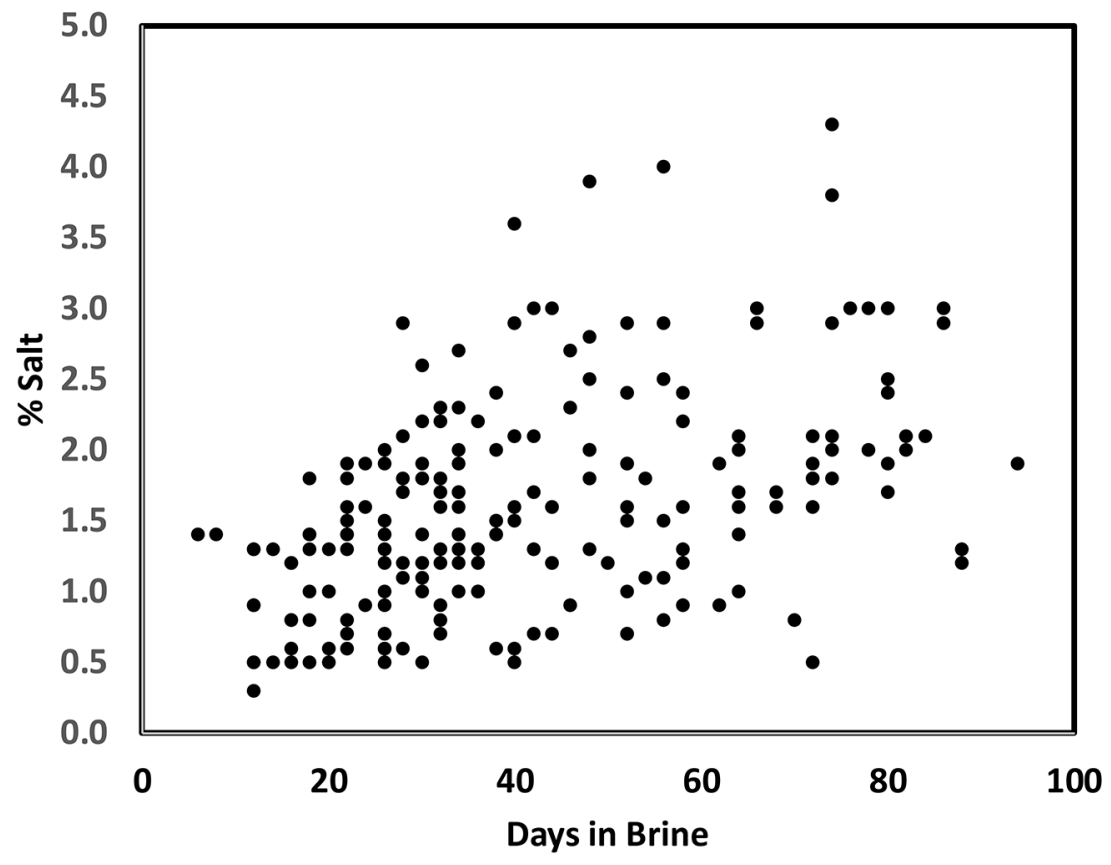

Figure 6.-Percentage salt in tuna vs. days in brine for DB2. 
ables to determine their impact on salt penetration into tuna. The results were then used as a guide to reduce salt penetration in tuna when freezing with salt brines. This was an industrial multiple regression study. It was developed to provide guidance on best handling practices, but not to use for predictive purposes. Salt brines needed to be, and have continued to be, used to chill and freeze tuna on vessels that catch large volumes of fish in a single set or day. Additional knowledge and understanding of how to use salt brines efficiently was needed to avoid the excess salt penetration that was occurring. The key findings then needed to be shared with the vessel crews. The findings and knowledge were exchanged during one-on-one discussions with the CEs of the tuna purse seiners while in port in the Caribbean, the Americas, and throughout the $\mathrm{Pa}$ cific Ocean.

The five chilling and freezing variables were tested in different models to determine their relative importance to salt penetration in tuna under different conditions. Some of the variables and impacts can be mitigated while other variables cannot be changed. For any given load of tuna delivered to a cannery, the SIZE and SPECIES cannot be changed, but the amount of time the fish spends in RSW and/ or brine and the thawing temperatures are actionable variables and can be fully controlled.

The variable SIZE was a significant variable, and it entered as the first or second most significant variable in every model. The physical explanation for the importance of SIZE is that the surface-area-to-volume ratio decreases as the tuna gets larger. The size data used was ordinal, when in fact the data is a continuous real number, so some information was lost. In a further scientific study, each fish should be weighed so more information would be available for use.

The variable DAYSRSW varied in significance depending on the model and database used. For salt levels above 3\%, Model 3 showed that the amount of time the tuna spent in RSW
Table 2.-Results of regression analysis for Model 2 (includes only cases with salt under $3.0 \%$ ).

\begin{tabular}{lclcccccc}
\hline Cases & Step & Variable & F & ADJ RSQ & Coef & S.E. & Sig \% & Beta \\
\hline 300 & 1 & DAYSBRIN & 111.9 & .27 & .014 & .001 & 100 & .49 \\
& 2 & SIZE & 59.2 & .39 & -.248 & .030 & 100 & -.37 \\
& 3 & DAYSRSW & 7.8 & .40 & .018 & .006 & 99 & .12 \\
& Constant & & & 1.510 & & & \\
& STD Error Estimate & & & .521 & & & \\
\end{tabular}

Table 3.-Results of regression analysis for Model 3 (includes only cases with salts $3.0 \%$ or greater).

\begin{tabular}{lclccccrc}
\hline Cases & Step & Variable & F & ADJ RSQ & Coef & S.E. & Sig \% & Beta \\
\hline 43 & 1 & DAYSRSW & 31.8 & .42 & .105 & .017 & 100 & .66 \\
& 2 & SIZE & 8.5 & .51 & -.590 & .203 & 99 & -.32 \\
& Constant & & & 3.856 & & & \\
& STD Error Estimate & & & .919 & & & \\
& & & & & &
\end{tabular}
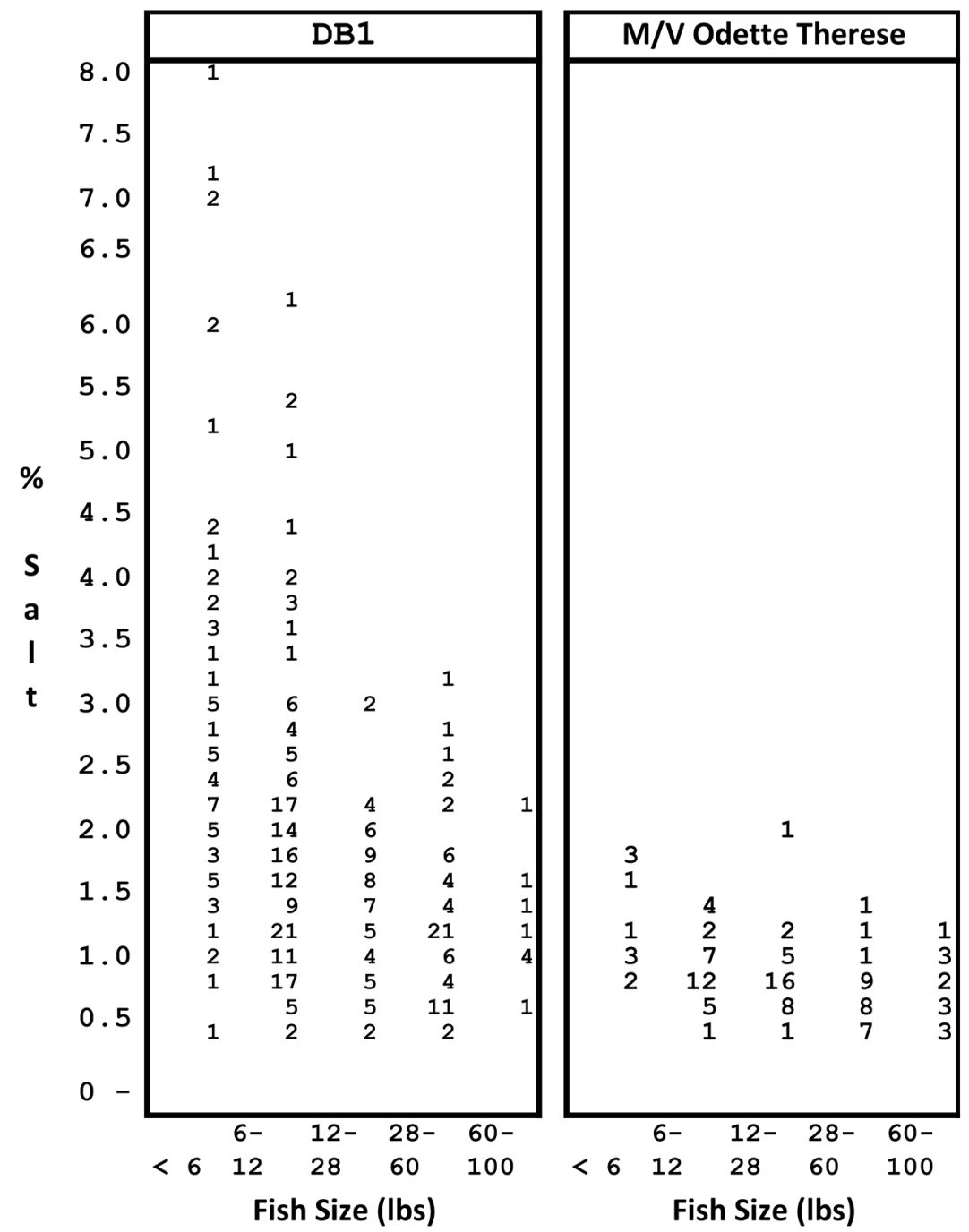

Figure 7.-Comparison of DB1 and DB3 (M/V Odette Therese) salt levels. The fish sampled in DB1 were held for extended times in RSW and brine. The fish from the $\mathrm{M} / \mathrm{V}$ Odette Therese were frozen and dried quickly. 
Table 4. - Results of regression analysis for Model 4 (all cases included, plus 3 interaction terms).

\begin{tabular}{lclcccccc}
\hline Cases & Step & Variable & F & ADJ RSQ & Coef & S.E. & Sig \% & Beta \\
\hline 332 & 1 & DAYSRSW & 86.3 & .20 & .18 & .016 & 100 & .88 \\
& 2 & DAYSRSW ${ }^{*}$ SIZE & 113.5 & .41 & -.04 & .006 & 100 & -.59 \\
& 3 & DAYSBRIN & 82.8 & .53 & .02 & .004 & 100 & .44 \\
& Constant & & & .402 & & & \\
& STD Error Estimate & & & .803 & & & \\
& & & & &
\end{tabular}

Table 5. - Result of regression analysis for Model 5.

\begin{tabular}{lclcccccc}
\hline Cases & Step & Variable & F & ADJ RSQ & Coef & S.E. & Sig \% & Beta \\
\hline 213 & 1 & SIZE & 187.8 & .47 & -.422 & .032 & 100 & -.60 \\
& 2 & DAYSBRIN & 55.2 & .58 & .013 & .002 & 100 & .34 \\
& Constant & & & 2.12 & & & \\
& STD Error Estimate & & & .5 & & & \\
\hline
\end{tabular}

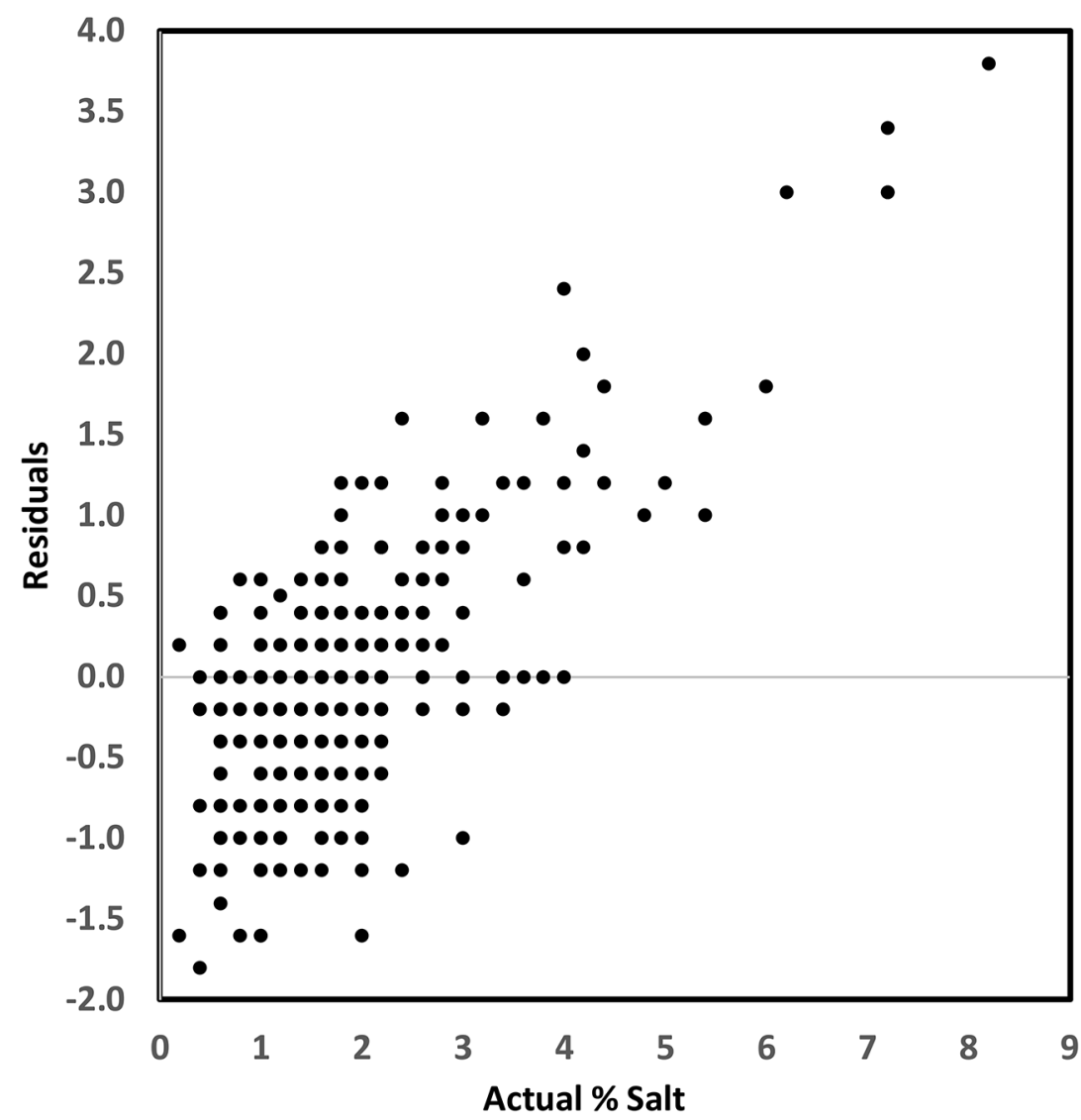

Figure 8.-Residuals vs. actual salts for model 1 (DB1).

before being brined was very significant. From Model 4, we learn that smaller tuna are more affected by the time spent in RSW than larger tuna. This fact has tremendous commercial significance: in that smaller fish should be stored in RSW for a shorter time before brining and freezing.

The variable DAYSBRIN contributed significantly to every model except the models where the database contained only cases with SALT\% greater than $3 \%$. In Model 2, using only cases with less than $3 \%$ salt, DAYSBRIN was the most important variable. In Model 5, with a database that contained only six cases with salts greater than 3\%, DAYSBRIN was the second variable to enter the equation after SIZE. The implications are that the tuna absorbs salt continuously when they are in brine, so simply drying the well(s) after freezing will reduce salt penetration. The frozen fish should be stored dry.

The data on unloading temperatures with fish thawed or tempered in brine was only available in DB2. Although the variable UNLDTEMP added only slightly to the equation, the addition was significant at the $99.5 \%$ level. The conclusion is that higher storage and unloading temperatures while the fish is held in brine contribute to higher salt levels. The frozen tuna should be unloaded dry and cold.

The variable SPECIES was not a factor in any of the models. Thus, the hypothesis that the amount of salt penetration in tuna flesh is different for YFN and SKJ of the same size was not shown to be true.

The implication from the results from Model 4 (the model where the variables were interacted) are that the smaller fish absorb more salt the longer they spend in seawater than larger fish. This may be because the smaller fish have thinner skin or deteriorate faster. Whatever the reason, it's apparent from this data that small fish need to be treated with care, and they are not as robust as larger fish.

Based on the results of this study, the following message was delivered to vessel management and crews starting in 1981:

1) Limit the time the fish spend in RSW to 5 days before brining the wells.

2) Dry the wells after the fish are frozen, maybe 3-5 days of frozen storage treatment in brine before drying.

3) Dry wells are cheaper in the long run.

a) Minimum salt penetration in the fish. 
Table 6. -A comparison of regression coefficients, Betas and RSQuared between Model 5 and Model 2.

\begin{tabular}{|c|c|c|c|c|c|c|c|c|c|}
\hline \multirow[b]{2}{*}{ Step } & \multicolumn{4}{|c|}{ Model 5} & \multicolumn{5}{|c|}{ Model 2} \\
\hline & Variable & COEF & BETA & $\mathrm{RSQ}$ & Step & Variable & COEF & BETA & $\mathrm{RSQ}$ \\
\hline 1 & SIZE & -.422 & -.60 & .47 & 1 & DAYSBRIN & .014 & .49 & .27 \\
\hline 2 & DAYSBRIN & .013 & .34 & .58 & 2 & SIZE & -.248 & -.37 & .39 \\
\hline \multirow[t]{2}{*}{3} & - & & & & 3 & DAYSRSW & .018 & .12 & .40 \\
\hline & Constant & & 2.12 & & & Constant & 1.510 & & \\
\hline
\end{tabular}

b) No electricity generated to run the brine pumps once the tuna is frozen and dried.

c) No pumping the brine against the coils on the surface of the wells, on the outside of the vessel; this warms the brine so it must be cooled again.

d) Dried wells require a minimal amount of refrigeration compared to maintaining frozen fish in brine.

4) Unload the fish dry and as cold as possible.

There was considerable pushback from the CEs regarding these ideas, but, after some documented successes, more and more CEs adopted the practices. In 1983, there was a real scarcity of fish in the ETP so many purse seiners made the long trip to the WTP to catch loads of tuna. The CE on the M/V Odette Therese decided to dry one pair of wells as a favor to one of the authors $\left(\right.$ DeBeer $\left.^{5}\right)$. When that appeared promising, he dried the second pair, and then so forth, until the entire vessel was dried for the return trip back across the Pacific Ocean. The fish were packed light for possible transshipment, so when they were unloaded frozen and dry at $-11^{\circ} \mathrm{C}\left(12^{\circ} \mathrm{F}\right)$ at the San Diego cannery $\left(\mathrm{DeBeer}^{5}\right)$. The average salts by size group, not shown, was about half that of DB1, and the maximum salt was $2 \%$, (Fig. 7) compared to a maximum salt of $8 \%$ in DB1.

The data collected, the results, the analysis, and conclusions made from this study and analysis were substantiated with the later studies on three more tuna boats in the mid-1980's. The solutions proposed could be implemented with just a little bit of prior planning, as indicated by the results from the M/V Odette Therese trip discussed earlier.
Based in part on these research results and fish quality problems in the tuna fleet, the United States Tuna Foundation (USTF) funded a program in the early 1980's in which three research trips were conducted to understand how to prevent salt penetration and other quality problems (Patterson and Burns ${ }^{14}$ ). That body of knowledge and the fish freezing temperature profiles obtained were used to develop a Tuna Refrigeration Manual (Burns, 1985). This publication was distributed to all of the U.S. vessel crews and served as a source of information to reinforce the at-sea tuna quality improvement program. It was extremely useful throughout the late 1980's and 1990 's and still is regularly referenced and distributed.

In the 1990's, there were some additional quality issues in the U.S. fleet so the USTF again funded two vessel trips to study these problems. This study produced another publication from the USTF in 1995: "If You Catch It, Freeze It" (USTF ${ }^{15}$ ). In 1995, seafood HACCP processing procedures were implemented (FDA, 1995) so the at-sea research had been very timely.

\section{Commercial Changes}

In the early 1980's, Van Camp Seafood instituted a payment system for purchasing fish with more refined size segregation. This system added

\footnotetext{
${ }^{14}$ Patterson, P., and F. D. Burns. 1984. Salt uptake, and histamine and honeycomb formation in brine frozen tuna. U.S. Tuna Found. Tech. Rep. (avail. at J. DeBeer's personal library (email: jdebeer2005@gmail.com).

${ }^{15}$ USTF. 1995. Recommendations for on-board handling on purse seine-caught tuna - IF YOU CATCH IT, FREEZE IT. USTF Tech. Bull., 4 p. (avail. at http://seafood.oregonstate.edu/. pdf $\% 20$ Links/Recommendations $\% 20$ for $\% 20$ OnBoard $\% 20$ Handling\%20of\%20Purse $\% 20$ SeineCaught $\% 20$ Tuna $\% 20-\% 20 U S T F . p d f .$, accessed 6 May 2018).
}

size groups and paid more for larger fish and less for smaller fish. There was also a price difference for fish unloaded with core temperature below $-10^{\circ} \mathrm{C}\left(14^{\circ} \mathrm{F}\right)$, lower salt levels, no other quality issues, and no physical damage (fish not smashed or broken). This payment system was a very successful program $\left(\right.$ DeBeer $\left.^{5}\right)$.

In 1984, the Van Camp cannery in San Diego was closed, and the Samoa Packing Factory in American Samoa was expanded to handle the volume from the San Diego cannery (Lord ${ }^{13}$ ). Many of the American-flagged tuna boats moved to the WTP to fish. The practice of packing the wells too tightly declined as the purse seiners started to pack the fish for transshipment on a frozen cargo bulk carrier. Tuna was loaded with $5-10 \%$ less fish in the well so the fish could be sent to Thailand, American Samoa, Ecuador, or Puerto Rico for processing. To receive a "clean bill of lading," the fish had to be "received on-board" at $-10^{\circ} \mathrm{C}$ $\left(14^{\circ} \mathrm{F}\right)$ or below (DeBeer ${ }^{5}$; Sylvester $\left.{ }^{7}\right)$. Fish loaded dry and cold and stored in a cold storage carrier, do not freeze to each other and are unloaded much faster at the cannery.

The Van Camp team worked with the tuna boats to light pack and dry the wells, so the fish for transshipment could either be unloaded dry or "floated" out in dense brine held at very cold temperatures. Fish that are thawed or tempered at the dock, and unloaded at $-4^{\circ} \mathrm{C}\left(24^{\circ} \mathrm{F}\right)$ to $-6^{\circ} \mathrm{C}\left(21^{\circ} \mathrm{F}\right)$ and then put into a cold storage held at lower temperatures of $-20^{\circ} \mathrm{C}\left(-4^{\circ} \mathrm{F}\right)$ will freeze together and make a large block or ball of fish that is very difficult to thaw and process efficiently (Colley ${ }^{6}$; Lord $\left.^{13}\right)$. Fish unloaded dry and frozen does not freeze together in cold storage which is a clear advantage for additional fish processing. 


\section{Current Regulations and Future Studies}

Why publish this paper now? The dynamics of the canned tuna supply chains into the United States and the world have changed significantly in the last 30-40 years. What had been a very dynamic tuna fleet, fleet support, and canning sector in southern California in the 1960's and 1970's is mostly gone. Factories in Thailand, Fiji, Ecuador, Colombia, and other countries unload and process whole round fish and sell canned tuna and frozen tuna loins into Europe and the United States (DeBeer $^{5}$ ).

Furthermore, in 1990, the FDA added two species of fish to the Canned Tuna SOI ${ }^{1}$ : frigate tuna, Auxis thazard; and bullet tuna, Auxis rochei (FDA, 1990.) These are very small fish, smaller than SKJ or YFN. When smaller anchovies got into sardine nets, Scofield (1951) described them as Christmas trees. The same thing happens to a tuna net when Auxis spp. are gilled in a tuna net $\left(\mathrm{DeBeer}^{5}\right)$. Their small size will have real implications for physical damage and salt penetration unless extreme care is taken, and the wells are dried quickly.

The WTP has the largest stock of tunas and the largest catch of SKJ by purse seiners in the world. For sustainability reasons, full retention of smaller fish has recently been implemented $\left(\mathrm{ISSF}^{16}\right)$. This requires that small fish cannot be discarded and must be purchased, if in useable condition. Smaller fish will absorb more salt on average than larger fish.

The smallest fish of the catch, which might have been sorted out and discarded in previous years, now must be retained, frozen, and shipped to market. These small fish will naturally absorb more salt if not treated properly at sea, when caught, chilled, and frozen. This means that the aver-

\footnotetext{
${ }^{16}$ ISSF(International Seafood Sustainability Foundation). 2011. Bycatch mitigation - 3.3 full retention of tunas (avail. at https://iss-foundation. org/what-we-do/verification/conservation-measures-commitments/bycatch-mitigation-3-3-fullretention-of-tunas/, accessed 12 May 2018).
}

age level of salt in the fish arriving in Thailand or other countries receiving transshipped fish is increasing. There are many instances where this fish is unusable for canned tuna packs unless it is blended with other lots of fish. Many companies now have traceability policies which makes this high-salt blending a traceability problem $\left(\right.$ DeBeer $\left.^{5}\right)$.

Although this article primarily describes methods to minimize salt penetration, the methods and practices to minimize salt penetration are also very appropriate to reduce the chances for other fish quality problems. As indicated in the introduction, there are now restrictions on catching fish on FADs, so the fishermen have to target school fish. The school fish visible at the surface are feeding on baitfish or crabs and will have food in their stomachs when loaded on board. This fish actually should be chilled and frozen faster than FAD fish to maintain its quality $\left(\right.$ DeBeer $^{5}$; Lord $\left.^{13}\right)$.

The tuna fleet ownership and management has changed, and the languages spoken on the vessels have changed. The fishermen on non-U.S. flag vessels may not understand the necessity to reduce sodium in the diet of the canned tuna consumer. They are also reluctant to remove the brine and dry the wells because they will need to purchase new salt to make new brine. Full-scale transshipment needs tons of replacement salt. The crews need to be made aware of the cost saving in other areas of the vessel operation such as reduced maintenance and reduced fuel usage to drive the generators and compressors during chilling and freezing the fish.

The following are recommended best practices to produce excellent quality purse seine fish:

1) Always have enough cold RSW $\left(-1^{\circ} \mathrm{C}\right.$ or $\left.30^{\circ} \mathrm{F}\right)$ or cold brine $\left(-15^{\circ} \mathrm{C}\right.$ or $\left.5^{\circ} \mathrm{F}\right)$ to receive the maximum expected catch. Do not catch the fish if you cannot chill and freeze it immediately.

2) Quickly transfer the fish from the net to the wells containing chilled RSW or cold brine. Brail fast.
3) Do not overpack the wells. This procedure will result in better chilling and freezing rates, reduce physical damage to the fish, and makes unloading easier and faster.

4) Restrict the time the tuna spends in the RSW to a maximum of 5 days, and then brine the well. If the well is only partially filled, spray the brine over the fish. If the fish size is small (i.e., Auxis spp.), the amount of time in RSW may need to be even less.

5) Freeze the fish completely to a minimum of $-12^{\circ} \mathrm{C}\left(10.4^{\circ} \mathrm{F}\right)$ backbone or core temperature.

6) Dry the wells (remove the brine) after the fish have been completely frozen.

7) Unload the fish dry and frozen at $-20^{\circ} \mathrm{C}\left(-4^{\circ} \mathrm{F}\right)$, if possible. The colder, the better for the quality of the fish.

\section{Acknowledgments}

John DeBeer (JDB) and Christopher W. Lord (CWL) worked for Van Camp Seafood starting in the late 1970's and through the 1980's. They implemented the Raw Tuna Quality Improvement Program on the tuna boats working out of San Diego, Puerto Rico, and American Samoa. They would like to acknowledge Ernest W. Peterson for his prescience in setting up this program at Van Camp Seafood Company. Fred Nolte and Javier Colley worked for competing companies in those years but faced the same problems. We thank Paul Krampe for his commercial leadership in developing the raw tuna quality standards for fish purchase decisions. JDB would like to thank Dr. James Beatty for introducing him to multi-variate analysis.

Jack (Lonnie) Fiero was the first $\mathrm{CE}$ we worked with who dried all his wells on a long voyage in the steel purse seiner era. In those years, Van Camp Seafood had many vessels arriving with loads of high-salt fish, and Fiero arrived from a 120-day trip on the M/V Rosa Oliva in 1982. When asked about his fish quality, he said, "It will be fine. My father told me, if you are on a long trip, just dry your wells, 
the fish will be fine, so I did." It was a very nice load of fish. Lionel Correia (since deceased) was the $\mathrm{CE}$ on the $\mathrm{M} / \mathrm{V}$ Odette Theresa that dried all the wells after a long and successful trip to the Western Pacific in 1983. JDB and CWL would like to thank these gentlemen for their help in those years.

The authors thank Mona Baumgartel and Jon Bell for their editorial help. The authors thank the reviewers for their suggestions to improve this manuscript.

\section{Literature Cited}

Almy, L. H., and E. Field. 1921. The preservation of fish frozen in chilled brine. I-The penetration of salt. Ind. Engr. Chem. 13:927930.

Burns, F. D. 1985. Tuna handling and refrigeration on purse seiners. U.S. Dep. Commer., NOAA Tech. Memo. NOAA-TMNMFS-SWR-011 (ftp://ftp.library.noaa.gov /noaa documents.lib/NMFS/SWFSC/TM NMFS_SWR/NOAA-TM-NMFS-SWR-011. pdf) (accessed 5 May 2018).

Castro, J. J., J. A. Santiago, and A. T. SantanaOrtega. 2002. A general theory on fish ag- gregation to floating object: an alternative to the meeting point hypothesis. Rev. Fish Biol. Fish. 11:255-277 (doi: https://doi. org/10.1023/A:1020302414472).

DeBeer, J. 1980. Cooperative dedicated vessel research program on the tuna-porpoise problem: overview and final report, United States. Mar. Mammal Comm. Rep. MMC-78/06, 37 p.

Farber, L. 1955. Refrigeration of tuna and sardines by sodium chloride brines. Food Technol. 9:141-147.

FDA (Food and Drug Administration). 1982. GRAS safety review of sodium chloride; policy notice; solicitation of views. 47 Fed. Regist. 26590 (18 June 1982), p. 26,590-26,595 (avail. online at https://cdn.loc.gov/service/11/ fedreg/fr047/fr047118/fr047118.pdf). 1990. Canned tuna; Amendment of the standard of identity. 55 Fed. Regist. 45795 (31 Oct. 1990), p. 45,795-45,798 (avail. online at http://cdn.loc.gov/service/ll/ fedreg/fr055/fr055211/fr055211.pdf)

1995. Procedures for the safe and sanitary processing and importing of fish and fishery products. 60 Fed. Regist. 65096 (18 Dec. 1995), p. 65,096-65,202 (avail. online at http://www.gpo.gov/fdsys/pkg/FR-1995$12-18 /$ pdf/95-30332.pdf).

Felando, A., and H. Medina. 2012. The origins of California's high-seas tuna fleet. J. San Diego Hist. 58:1-40.

Godsil, H. C. 1938. The high seas tuna fishery of California. Calif. Fish Bull. 51, 41 p.
Goulding, I. 2000. Refrigerated transport of frozen tuna. INFOFISH Int. 6:48-53.

Hair, J. F., Jr., R. E. Anderson, R. L. Tatham, and B. J. Grablowsky. 1979. Multivariate data analysis with readings. PPC Books, Tulsa, Oklahoma, $360 \mathrm{p}$.

Karrick, N. L., and C. E. Thurston. 1967. Proximate composition and sodium and potassium contents of four species of tuna. Fish. Indust. Res. 4:73-81.

Lang, O. W., and L. Farber. 1939. The preservation of tuna by chilled brines: a progress report. In Proc. Sixth Pac. Sci. Cong., Sect. on Oceanogr. and Mar. Biol, p. 281-289. Pac. Sci. Congr., Berkeley, Calif.

Lassen, S., and J. Rawlings. 1959. A manual for refrigeration practice for tuna clippers. Calif. Fish Canners Assoc., 70 p. Copy on file at John DeBeers' personal library (jdebeer2005@gmail.com).

Scofield, W. L. 1951. Purse seines and other roundhaul nets in California. Calif. Fish Bull., 81, 83 p.

Slavin, J. W., and R. Finch. 1969. Design of systems for freezing tuna at sea. In R. Kreuzer (Editor), Freezing and Irradiation of Fish, p. 80-84. Fishing News (Books) Ltd., Lond.

Wartella, E. A., A. H. Lichtenstein, and C. S. Boon (Editors). 2010. Examination of frontof-package nutrition rating systems and symbols: Phase I report. Natl. Acad. Sci., Wash., D.C., 140 p.

Wright, B. 1991. Pole fishing for tuna, 19391941. J. San Diego Hist. 37(3):160-193. 